\title{
Accessible genomes move closer
}

\section{NEW YORK}

Rarely do research subjects attend scientific meetings. Yet at the inaugural Cold Spring Harbor Personal Genomes meeting this month on Long Island in New York, the Nobelprizewinning biologist James Watson sat in the front row as other researchers dissected his genetic vulnerabilities via a PowerPoint presentation. So far, Watson says, it has not been a particularly profound experience: "I haven't really learned anything, except that I'm lactose intolerant."

Other than Watson, only three people have had their genomes sequenced in full, but other sequencing efforts are under way, including the Personal Genome Project and the 1,000 Genomes Project. And researchers may soon be able to start linking this flood of personal genomic data to the biology of individual humans and the species.

The Cold Spring Harbor meeting marked the first steps in that direction. "It really feels like a new era is starting," says Martin Reese, a bioinformaticist at Omicia, which develops genome interpretation software in Emeryville, California. "People don't quite know how to apply these new techniques and technologies to human genomes, but very soon, they will."

One new approach tackles the human germline mutation rate - how much new genetic variation is born into each generation - which should inform theories of human evolution. At the Baylor College of Medicine in Houston, Texas, a group led by Richard Gibbs is sequencing and comparing thousands of genes of parents and their children. The preliminary data, reported at Cold Spring Harbor, suggest that the mutation rate is much higher than some estimates, but that has also been the case with direct measurements in other species, such as the fruitfly (C. Haag-Liautard et al. Nature 445, 82-85; 2007). Other scientists are using sequencing to look at the biological consequences of variation among individuals. Michael Snyder of Yale University in New Haven, Connecticut, is cataloguing the interactions between DNA

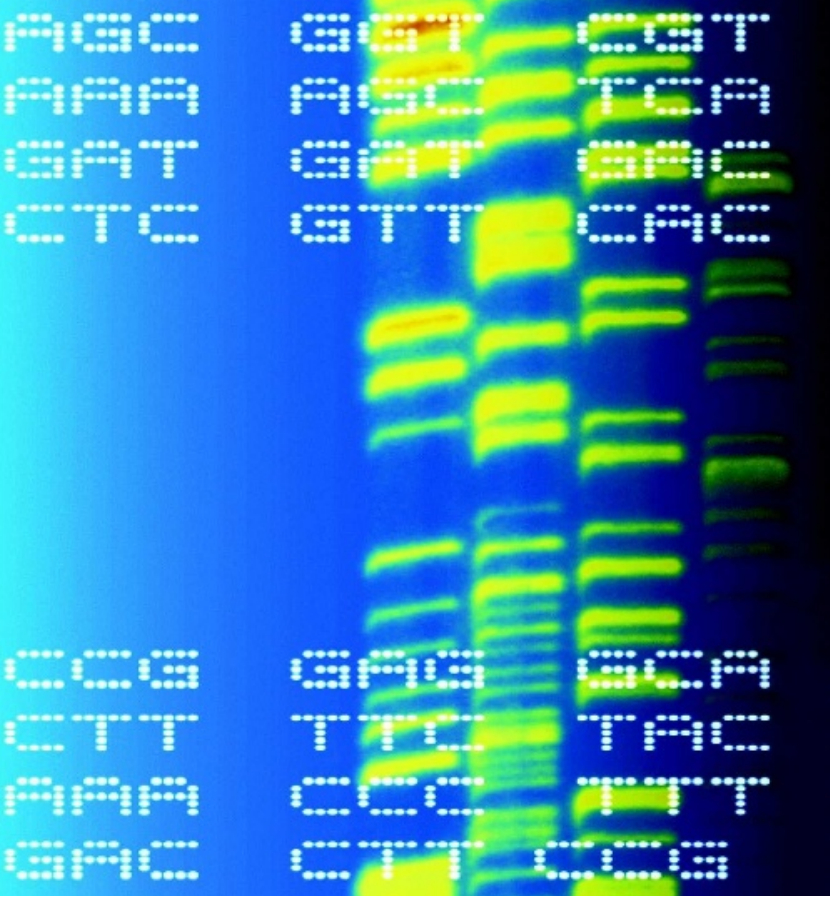

Exciting as it is, the prospect of multiple genomes per hour poses daunting data challenges, says Elaine Mardis, co-director $\dot{\Sigma}$ of the Genome Sequencing Center at Washington University in St Louis. She is leading a project to catalogue all the mutations in one patient's cancer, an acute myeloid leukaemia. To interpret what these mutations mean, Mardis's group had to search numerous databases of variation - a job that will become more onerous, she says, as new projects contribute more data. She says that the field needs some kind of 'knowledgebase' to incorporate all that we already know and will soon learn about genomic variation and its links to biology and disease.

Reese is already trying to do that with Omicia, which is developing tools to analyse individual human-genome

and the enzyme RNA polymerase II - which helps to transcribe DNA into RNA — in cells containing human DNA. In each cell line, Snyder sequences the DNA wherever it binds to RNA polymerase II, thus obtaining a map of active transcription sites in each individual's genome. By comparing such maps, Snyder is discovering how human genetic differences are interpreted by the cell. "We're seeing some differences between individuals' DNA, and that will be the first translation of genetic differences to functional differences," Snyder says.

\section{Ten-minute genomes}

Snyder's work would not have been possible without the high-speed sequencing machines that he and many others at the conference are using (see Nature 448, 10-11; 2007). Pacific Biosciences, in Menlo Park, California, aims to build a machine that can sequence entire human genomes in ten minutes. The company said at the meeting that it is testing its technology on a bacteriophage, and it is now sequencing 550-base-pair segments of DNA. Researchers will soon see for themselves: the company begins an in-house early-access programme next year. sequence data against scientific databases that link genetic variants to disease. The goal is to interpret how each of an individual's genetic variants influences his or her disease risk, then display that information in an accessible format that could, for instance, be used by a doctor interacting with a patient.

Reese was one of the few scientists at the Cold Spring Harbor meeting who spoke about how the public will use genomic data. Yet it is not too early to think so far ahead - and might indeed be too late. On 21 October, the participants in the Personal Genome Project - run by George Church, a geneticist at Harvard Medical School - posted their gene sequences on the Internet (see Nature doi:10.1038/news.2008.1182; 2008). They are also providing extensive medical and nonmedical information about themselves so that anyone can interpret their data.

And already, anyone can buy a personal genomics test to analyse his or her own genetic variation. Indeed, the human desire for self-knowledge driving these ventures was embodied throughout the Cold Spring Harbor conference in the presence of Watson. Whether this desire is fulfilled or frustrated could now depend on the others who were in the room. Erika Check Hayden See Editorial, page 1007. 